\title{
Prospective evaluation of gastric neurostimulation for diabetic gastroparesis in Canada
}

\author{
Himanish Panda BHSc${ }^{1}$, Philip Mitchell MD², Michael Curley MD ${ }^{1}$, Michelle Buresi MD $^{1}$, \\ Lynn Wilsack $\mathrm{MSc}^{1}$, Christopher N Andrews MD MSc ${ }^{1}$
}

H Panda, P Mitchell, M Curley, M Buresi, L Wilsack, CN Andrews. Prospective evaluation of gastric neurostimulation for diabetic gastroparesis in Canada. Can J Gastroenterol Hepatol 2015;29(4):198-202.

BACKGROUND: The efficacy of gastric neurostimulation therapy for diabetic gastroparesis (GP) in a 'real-life' Canadian setting has not been assessed.

AIMS: To assess changes in health-related quality of life (QoL), weekly vomiting frequency (WVF), total symptom score (TSS) and health care utilization 12 months before and after gastric neurostimulator implantation in a diabetic GP cohort.

METHODS: Medication-refractory diabetic GP patients $(n=7$, four female, mean age 42 years) were prospectively recruited from 2008 to 2012. QoL scores were self-administered and obtained at baseline, 24 and 48 weeks postimplantion. WVF and TSS were assessed similarly. Health care usage, measured as hospitalization frequency and medication cost, was obtained six and 12 months before and after implant. Changes from baseline to six and 12 months for all outcomes were compared.

RESULTS: The mean ( \pm SD) QoL according to EuroQol was significantly better at 24 weeks after the baseline measurement (baseline $29 \pm 5,24$ weeks $52 \pm 7 ; P=0.03)$. The mean improvement in TSS was significantly better at one year postintervention (baseline score $35 \pm 5$ versus 12 months $27 \pm 3 ; \mathrm{P}=0.03$ ). Changes in Short-Form 36 Health Survey and WVF were not significant. Days of GP-related hospitalization were highly variable but decreased from a median of 71 days (range 0 to 227 days) to 29 days (range two to 334 days) one year before and after surgery, respectively $(\mathrm{P}=0.735)$. Outpatient medication costs did not decrease to a significant extent.

CONCLUSION: Gastric neurostimulation for diabetic GP appeared to show some beneficial palliative effects overall in the present small open-label series, but the effect is highly variable among patients, and placebo effect cannot be ruled out.

Key Words: Canada; Diabetic gastroparesis; Enterra therapy; Neurostimulation Gastroparesis (GP) is a disorder manifested by delayed gastric Jemptying in the absence of mechanical obstruction $(1,2)$. Patients with severe GP experience frequent hospital admissions and have a poor quality of life ( $\mathrm{QoL}$ ) (1). There are many causes of GP, although the disorder is most often associated with longstanding diabetes and its neuropathic sequelae. Clinical presentations of GP range from mild to severe, and can vary in any combination of nausea, vomiting, epigastric pain and distress, abdominal fullness or bloating, early satiety, heartburn and loss of appetite (3).

Traditional management of GP has centred around supportive management (4). Reduction of symptoms is typically achieved with prokinetic and antiemetic medication to stimulate and coordinate gastroduodenal motility and treat nausea, respectively (4). Feeding jejunostomy to bypass the stomach and maintain nutrition is a palliative strategy; however, symptoms may persist.

\author{
Lévaluation prospective de la neurostimulation \\ gastrique pour la gastroparésie diabétique au \\ Canada
}

HISTORIQUE : L'efficacité du traitement par neurostimulation gastrique pour la gastroparésie (GP) diabétique n'a pas été évaluée dans un milieu canadien « réel ».

OBJECTIFS : Évaluer les modifications à la qualité de vie liée à la santé (QdV), la fréquence de vomissements hebdomadaires (FVH), le score global de symptômes (SGS) et l'utilisation des services de santé 12 mois avant et après l'implantation d'un neurostimulateur gastrique dans une cohorte de GP diabétique.

MÉTHODOLOGIE : Les patients atteints de GP diabétique réfractaire aux médicaments ( $n=7$, quatre femmes, âge moyen de 42 ans) ont fait l'objet d'une étude prospective réalisée de 2008 à 2012. Les scores de QdV on été obtenus au moyen de questionnaires auto-administrés colligés en début d'étude, 24 et 48 semaines après l'implantation. La FVH et le SGS ont été évalués de la même façon. L'utilisation des soins de santé, mesurée par la fréquence d'hospitalisations et le coût des médicaments, a été mesurée six et 12 mois avant et après l'implantation. Les chercheurs ont comparé les modifications entre le début de l'étude et six et 12 mois plus tard à l'égard de tous les résultats.

RÉSULTATS : D'après le questionnaire EuroQol, la QdV moyenne ( \pm ÉT) était plus importante 24 semaines après la mesure de départ ( $29 \pm 5$ en début d'étude, $52 \pm 7$ au bout de 24 semaines; $\mathrm{P}=0,03$ ) L'amélioration moyenne du SGS était beaucoup plus substantielle un an après l'intervention (score de départ $35 \pm 5$ par rapport à $27 \pm 3$ au bout de 12 mois; $\mathrm{P}=0,03)$. Les changements au questionnaire court en 36 questions et la FVH n'étaient pas significatifs. Les jours d'hospitalisation liés à la GP étaient hautement variables, mais ont reculé d'une médiane de 71 jours (plage de 0 à 227 jours) à 29 jours (plage de deux à 334 jours) un an avant et après l'opération, respectivement $(\mathrm{P}=0,735)$. Le coût des médicaments en milieu ambulatoire n'a pas diminué de manière significative.

CONCLUSION : La neurostimulation gastrique pour la GP diabétique semble avoir des effets palliatifs globaux bénéfiques dans cette petite cohorte ouverte, mais l'effet est hautement variable, et on ne peut pas écarter un effet placebo.

\footnotetext{
${ }^{1}$ Division of Gastroenterology; ${ }^{2}$ Division of General Surgery, Cumming School of Medicine, University of Calgary, Calgary, Alberta

Correspondence: Dr Christopher N Andrews, University of Calgary, 6D34, 3280 Hospital Drive Northwest, Calgary, Alberta T2N 426.

Telephone 403-592-5015, e-mail candrews@ucalgary.ca
}

Received for publication January 20, 2015. Accepted January 25, 2015 
A small pilot study of Enterra therapy was undertaken in Calgary (Alberta) from 2008 to 2012. The aim of the present study was to assess changes in health-related QoL before and after implantation of Enterra therapy in patients with severe drug-refractory GP secondary to diabetes mellitus (DM) and to compare health care utilization and symptoms for the year before and the year following implantation.

\section{METHODS}

The present analysis was a single-centre prospective pilot study of Enterra therapy for a small, highly selected population of diabetic patients with overwhelming symptoms due to medically refractory GP.

\section{Subjects}

Patients residing in southern Alberta between 18 and 65 years of age with insulin-treated DM and GP confirmed previously with gastric emptying scintigraphy ( $>10 \%$ retention at $4 \mathrm{~h}$ ), who were demonstrably refractory to other GP treatment were invited to participate in the present study. Each participant had a clinical diagnosis of diabetic GP for at least one year, with a severity requiring at least two prokinetic and/or antiemetic medications or requiring jejunal feeding by any route; no alternative causes for symptoms found on gastroscopy within the past year; and was deemed medically fit to undergo surgery. Exclusion criteria included any clinical evidence (including physical examination or electrocardiography) that could pose surgical or other safety risks to the patient, previous gastrointestinal surgery, use of narcotics that could not be stopped before entering the study, and pregnant or breastfeeding women. Any patient on peritoneal dialysis or with an intra-abdominal transplant (or being considered for same) was also excluded. The present study was approved the Conjoint Health Research Ethics Review Board at the University of Calgary, Alberta. Each participant gave written informed consent before study procedures were performed. The study was funded through the local health board and received no funding from the neurostimulator manufacturer.

\section{Implant procedure}

Enterra therapy was implanted using laparoscopic lead placement into the gastric antral muscularis, with a small open skin incision to create the pocket for the pulse generator. The surgery required approximately 60 min of operating room time, using a standard laparoscopic tray. The procedure is technically straightforward and is described elsewhere (10). Patients generally required a one to two day inpatient stay after implantation.

\section{Health care costs}

Cumulative health care costs incurred in the 12 months before Enterra implantation were compared with those incurred from the day of the Enterra placement surgery and 12 months thereafter. These data were obtained from Alberta Health Services (AHS).

The number of inpatient hospitalization days was determined through use of the hospital separations and physicians claims databases at AHS using a diagnostic-related grouping methodology to ensure only GP-related stays were included. Outpatient drug costs were calculated by assigning a value for each drug (per tablet or single dose) based on AHS and Alberta Blue Cross data when available, and on prices listed on www.CanadaDrugs.com (June 2013) when Alberta Blue Cross data were unavailable, and then multiplying by the quantity of the drug prescribed. Only drugs related to GP, specifically prokinetics and antiemetics, were included in the present analysis.

\section{Questionnaires}

QoL questionnaires: At baseline, 12, 24 and 48 weeks postimplant, subjects answered three QoL questionnaires: Functional Living IndexEmesis (FLIE), a validated assessment of QoL specifically related to nausea and vomiting in the previous five days (11); the 36-item ShortForm Health Survey (SF-36) questionnaire $(12,13)$, a validated measure of global QoL with both mental and physical domains; and the EuroQol 5D-3L (EQ-5D) with visual analogue scale (EQ-VAS), a preference-based QoL questionnaire that has been used in patients with gastrointestinal diseases $(14,15)$. All questionnaires were selfadministered by the patients.

Symptom questionnaires: At baseline, 12, 24 and 48 weeks postimplant, subjects completed a vomiting diary for the two weeks before the visit, a total symptom score (TSS) of GP symptom severity determined by the sum of the severity ratings of six symptom subscores (vomiting, nausea, early satiety, bloating, postprandial fullness and epigastric pain). Symptoms were rated on a five-point scale as $0=$ absent, $1=$ mild (not influencing usual activities), 2 = moderate (diverting from, but not requiring modifications of, usual activities), 3 = severe (influencing usual activities severely enough to require modifications) and $4=$ extremely severe (requiring bed rest). This is a frequently used score in the GES literature (16-18).

\section{Data and statistical analysis}

The primary outcome measures of mean change in FLIE, SF-36 (mental and physical composite scores), EQ-5D (scored with USA TTO dataset) and EQ-VAS from baseline to 24 weeks and 48 weeks postimplant were compared using the Wilcoxon signed-rank test. The means of number of days hospitalized and outpatient medication costs for the year before and the year postintervention were compared using Wilcoxon signed-rank test and Student's $t$ test, respectively.

For secondary outcome measurements of weekly vomiting frequency and TSS, differences in means were compared using the Wilcoxon signed-rank test; $\mathrm{P}<0.05$ was considered to be statistically significant. In addition, records were analyzed for evidence of surgical complications and changes in use of prokinetic and antiemetic medications.

\section{RESULTS}

In total, seven medication-refractory diabetic GP patients (four female, mean age 42 years) were prospectively recruited in the Calgary area between 2008 and 2012. No surgical complications directly related to the implantation occurred. All implanted units were functional during the study. Four of seven patients have died at the time of the present report: three within two years of implantation and one died two years and two months postimplantation; however, none died during the study period. Causes of death varied, although all were related to diabetic sequelae.

\section{QoL measures}

The mean FLIE scores postimplant showed numerical improvement shortly after intervention, then trended back to baseline values by week $48(\mathrm{P}=0.753)$. Note that in this metric, larger values indicate a better QoL. Neither SF-36 physical nor mental scores showed significant improvement at any time postimplant with respect to baseline $(\mathrm{P}=0.173$ at week 48 for the SF-36 physical scores; $\mathrm{P}=0.172$ at week 48 for SF-36 mental scores).

EQ-5D scores showed improvement from baseline, from a mean of 0.387 (where 1 is considered perfect health) to 0.553 at 24 weeks and 0.550 at 48 weeks, but neither measure achieved statistical significance. EQ-VAS scores were generally low and well below 100, which represents the best possible health imaginable. The baseline score was 29 , increasing significantly to 52 at week $24(\mathrm{P}=0.034)$ and 46 at week $48(\mathrm{P}=0.058)$. Data are shown in Figure 1.

\section{Symptoms}

Although weekly vomiting frequency decreased substantially from an average baseline score of 27.9 to $9.6,4.4$, and 6.8 at weeks 12,24 , and 48 , respectively, the improvement was not statistically significant despite the apparent clinical benefit ( $\mathrm{P}=0.116$ at week 48 ). The mean TSS score showed a significant improvement 48 weeks postimplantation compared with baseline $(\mathrm{P}=0.046)$. The averaged TSS score at week 48 was 27.2 compared with baseline (35.0). Note that in this metric, smaller values indicate improvement. Data are shown in Figure 2.

\section{Health care usage}

Hospitalization length was highly variable among the seven patients, as shown in Figure 3. The total number of days hospitalized decreased 


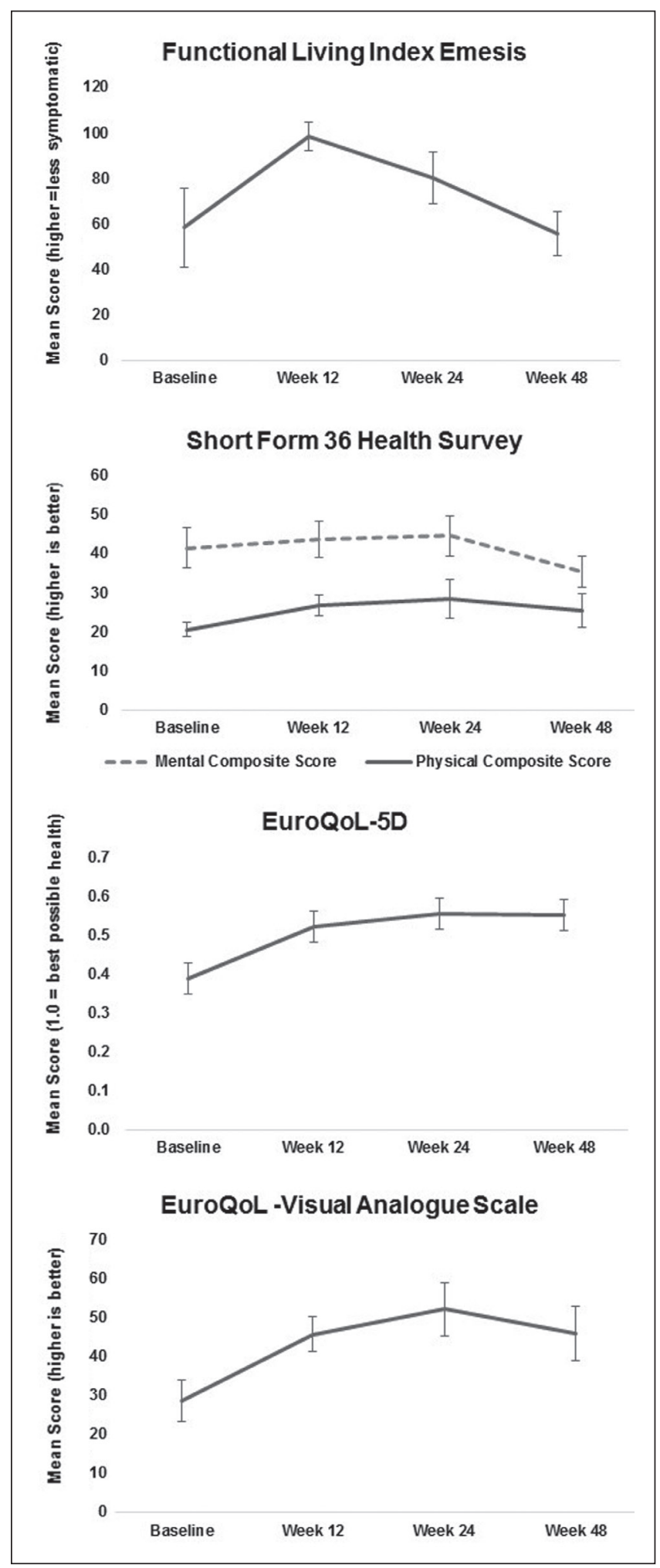

Figure 1) Quality of life questionnaire scores

after the intervention, going from 769 days (median 72 days) days in the year before surgery to 621 days (median 40 days) in the year after the surgery. Total number of days hospitalized due to GP symptoms as the primary reason also decreased after the intervention, going from 580 days (median 71 days) in the year before surgery to 473 days (median 29 days) in the year postintervention. Given the variability, these reductions in hospital usage were not significant $(\mathrm{P}=0.735)$.

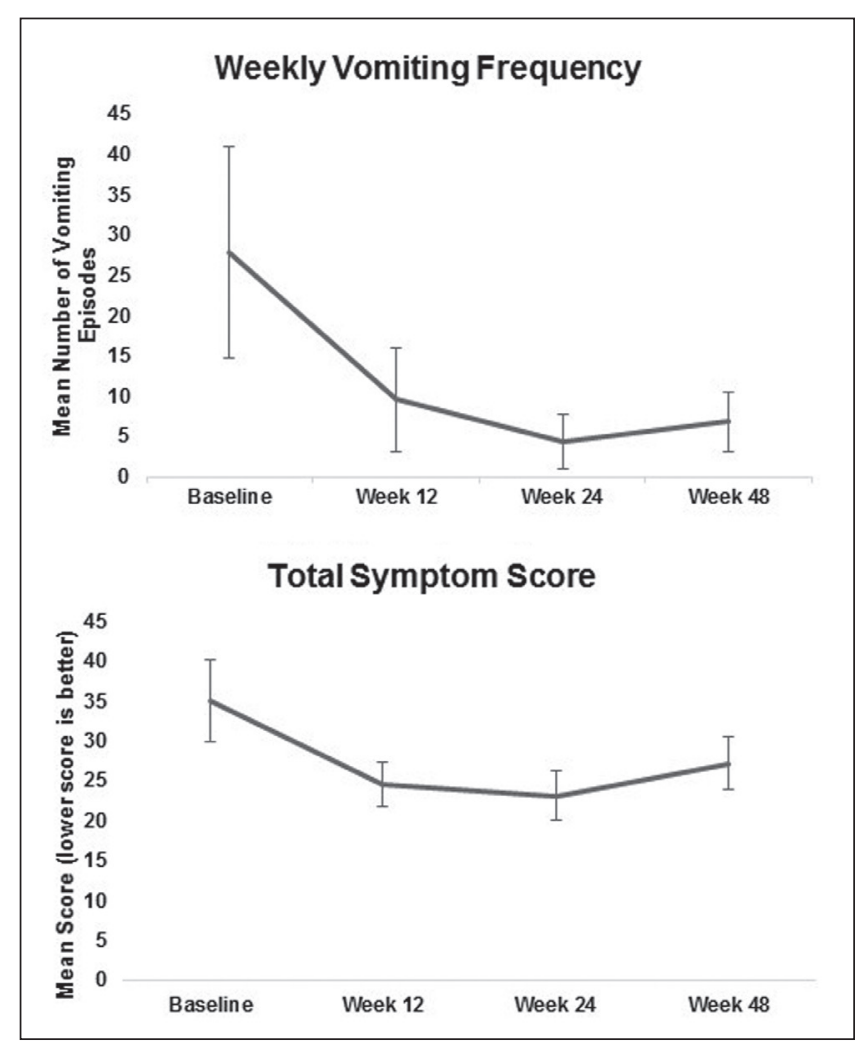

Figure 2) Gastroparesis symptoms measures

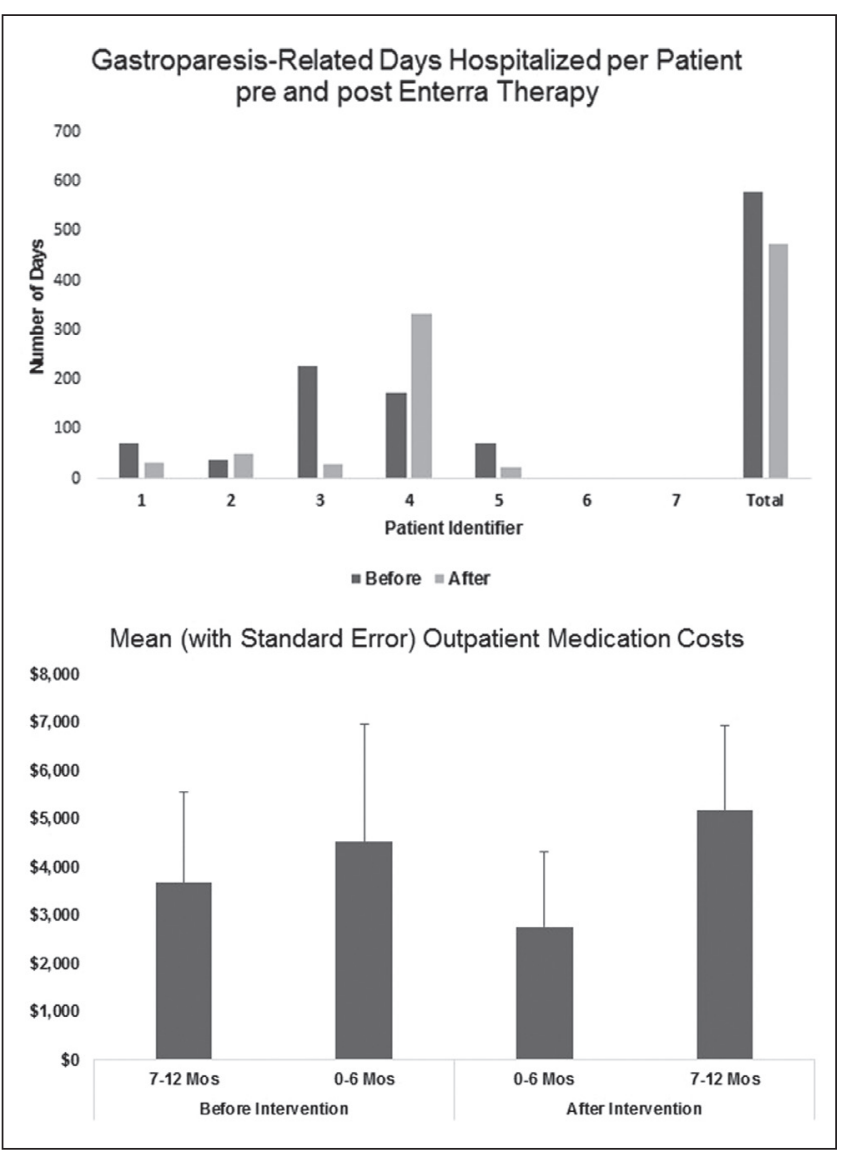

Figure 3) Health care-related costs, before and after Enterra (Medtronic, USA) implantation. Mos Months 
Mean outpatient medication costs were $\$ 8,199$ for the year before and $\$ 7,945$ for the year postimplant. There was a $39 \%$ decrease in mean medication costs when comparing costs at six months pre- and postintervention $(\$ 4,517$ and $\$ 2,764$, respectively); however, this difference was not significant $(\mathrm{P}=0.10)$. All patients were using prokinetics and antiemetics at 12 months postimplantation.

\section{DISCUSSION}

The present study is the first to report the outcomes of Enterra therapy in the 'real-world' setting since approval in Canada. From a qualitative perspective, it is clear that some patients improved significantly, whereas others did not appear to benefit. There was a general trend toward improvements in symptoms and QoL overall, although most end points did not reach statistical significance.

The present study had two main limitations, the first of which was small sample size. There were several reasons for this including the relative rarity of the disease and exclusions for other comorbidities. Because individuals with end-stage diabetic complications, such as GP, almost invariably have other complications, such as nephropathy and peripheral neuropathy, many patients failed screening due to the need for peritoneal dialysis and/or the use of narcotics, respectively. Although our group has performed other Enterra implantations for out-of-province patients, they were not included in the present study because we would not have been able to capture the hospitalization and medication use data. The other limitation of the present study was that it was not blinded and, thus, had no control for the placebo effect. Previous controlled studies have shown similar levels of improvement in groups with and without the intervention, suggesting the presence of a placebo effect $(1,19)$. However, given that all previous medical interventions failed to alleviate symptoms in this cohort, at least some of the positive results observed in the present study could be attributed to the implanted neurotransmitter.

The mechanism of action of GES is not completely understood (20). Contrary to common misperception, Enterra is not a 'pacemaker' analogous to those used in cardiac applications, although the hardware appears similar. Although entrainment ('pacing') of the intrinsic gastric electrical activity is possible, it requires more energy than an implantable battery can provide and, in fact, can cause significant patient discomfort (21). The low-energy, high-frequency stimulation used in the Enterra system does not appear to work by improving gastric emptying; it is, thus, not a true pacemaker and neurostimulator is a more appropriate term. It was previously believed that it may function via vagal afferent stimulation and subsequently increased central descending inhibition (22), similar to spinal cord stimulation for chronic pain (23); however, the evidence is conflicting because highfrequency GES also works in patients with vagotomy (24). Other animal studies have suggested it may work through modulation of gastric spinal afferent nerves (25).

The American Gastroenterological Association Technical Review on the diagnosis and treatment of GP quoted an unpublished study of patients with severe GP that estimated health care costs to be an average of USD\$6,972 per patient per month (4). Most expenditures were attributed to requirements for hospitalization and temporary or longterm use of intravenous alimentation (parenteral nutrition). In addition, diagnostic tests for patients with presumed GP are associated with significant costs, especially for endoscopy and gastric emptying scintigraphy tests (4). The cost of implanting the Enterra therapy system in the US is approximately $\operatorname{USD} \$ 30,000$, and is covered by Medicare as well as some private health insurance companies (26). The total cost of the device hardware per patient is approximately CAD $\$ 12,000$. Costs of diagnostic tests, surgical intervention (laparoscopy or laparotomy) to implant the device, hospitalization and followup are supplemental.

Although a substantial literature base assessing the efficacy of GES for GP has accumulated, all of the studies (with the exception of two) have been uncontrolled open-label case series similar to the present analysis. The two published randomized sham-controlled studies (in which the device was implanted and patients were blinded as to whether the device was turned on or off), were both negative in meeting their primary end point $(19,27)$. Two meta-analyses have subsequently reviewed this literature, suggesting that the benefits of GES for GP are substantial for symptom reduction and gastric emptying, with the caveat of the limitations of uncontrolled studies $(28,29)$. This is a major caveat, however, because the numbers of patients in the uncontrolled studies were significantly greater than those in the controlled studies and would disproportionately favour positive conclusions.

The Alberta Heritage Foundation for Medical Research completed a health technology assessment on GES in 2006, which concluded that there was insufficient evidence to determine the efficacy of the therapy, and that routine use of the technology was not recommended (26). Based on current data since that time, and including the results of the present study, it is unlikely that those conclusions would be altered. To our knowledge, GES is not regularly offered publicly or privately anywhere in Canada.

However, more recent guidance from the United Kingdom National Institute for Health and Care Excellence (NICE) concluded that current evidence on the efficacy and safety of GES for GP is adequate to support the use of this procedure (30). The Committee concluded that the evidence of efficacy was adequate only after prolonged debate about the design of the available randomized trials, and also noted the possibility of a placebo response in most of the evidence. Furthermore, the NICE Committee also acknowledged that GP can be a highly debilitating condition with very few treatment options, and took into account anecdotal patient commentaries describing substantial improvements in QoL with GES. Clinicians are advised to inform patients considering the procedure that some patients do not receive any benefit from it (30). This NICE recommendation deviates from their typical guidance, which is generally significantly more evidence focused. It suggests they have adopted a similar stance to the Humanitarian Device Exemption given to GES in the US, whereby efficacy is not required to be proven for devices used in small populations with significant suffering.

\section{CONCLUSION}

In the present small study involving an end-stage diabetic GP population, the palliative effect on symptoms was witnessed and sustained to one year; however, the magnitude of the placebo effect was not estimable due to the study design. There did not appear to be any signal suggesting any improvement in hospitalization rate or medication costs, but the study was almost certainly underpowered given the variability of these measures. Furthermore, not all patients experienced a beneficial effect. The low morbidity of the implantation procedure and the modest cost compared with hospitalization or chronic medical therapy for GP make it reasonable to consider as a last-resort option; however, there is no certainty, based on the present study or others, that either symptoms or costs will improve for any given patient. Thus, any further funding for GES should be directed toward specialized multidisciplinary clinics with a focus on research and improvement of the technology.

DISCLOSURES: The authors have no financial disclosures or conflicts of interest to declare.

\section{REFERENCES}

1. Abell TL, Bernstein RK, Cutts T, et al. Treatment of gastroparesis: A multidisciplinary clinical review. Neurogastroenterol Motil 2006;18:263-83.

2. Bielefeldt K. Gastroparesis: Concepts, controversies, and challenges. Scientifica (Cairo) 2012;2012:424802.

3. Bortolotti M. Gastric electrical stimulation for gastroparesis: A goal greatly pursued, but not yet attained. World J Gastroenterol 2011;17:273-82. 
4. Parkman HP, Hasler WL, Fisher RS. American Gastroenterological Association medical position statement: Diagnosis and treatment of gastroparesis. Gastroenterology 2004;127:1589-91.

5. McCallum RW, Lin Z, Forster J, Roeser K, Hou Q, Sarosiek I. Gastric electrical stimulation improves outcomes of patients with gastroparesis for up to 10 years. Clin Gastroenterol Hepatol 2011;9:314-9,e1.

6. McKenna D, Beverstein G, Reichelderfer M, Gaumnitz E, Gould J. Gastric electrical stimulation is an effective and safe treatment for medically refractory gastroparesis. Surgery 2008;144:566-72.

7. Health Canada Medical Devices Active License Listing, License Number 60264. <http://webprod5.hc-sc.gc.ca/mdll-limh/startdebuter.do?lang=eng $>$ (Accessed July 17, 2014).

8. U.S. Food and Drug Administration. Medical Devices I Device Approvals, Denials and Clearances, H990014, Enterra ${ }^{\mathrm{TM}}$ Therapy System, formerly named Gastric Electrical Stimulation (GES) System. < http://www.accessdata.fda.gov/scripts/cdrh/cfdocs/cftopic/ pma/pma.cfm?num $=$ H990014 $>$ (Accessed July 23, 2014).

9. U.S. Food and Drug Administration. Medical Devices I Humanitarian Device Exemption. <http://www.fda.gov/medicaldevices/ deviceregulationandguidance/howtomarketyourdevice/ premarketsubmissions/humanitariandeviceexemption/default.htm> (Accessed September 16, 2014).

10. Brody F, Nam A, Drenon E, Ali A, Soffer E. Laparoscopic insertion of gastric electrodes for electrical stimulation. J Laparoendosc Adv Surg Tech A 2007;17:1-6.

11. Martin AR, Pearson JD, Cai B, Elmer M, Horgan K, Lindley C. Assessing the impact of chemotherapy-induced nausea and vomiting on patients' daily lives: A modified version of the Functional Living Index-Emesis (FLIE) with 5-day recall. Support Care Cancer 2003;11:522-7.

12. Velanovich V. Quality of life and symptomatic response to gastric neurostimulation for gastroparesis. J Gastrointest Surg 2008;12:1656-62.

13. Ware JE Jr, Gandek B. Overview of the SF-36 Health Survey and the International Quality of Life Assessment (IQOLA) Project. J Clin Epidemiol 1998;51:903-12.

14. Konig HH, Ulshofer A, Gregor M, et al. Validation of the EuroQol questionnaire in patients with inflammatory bowel disease. Eur J Gastroenterol Hepatol 2002;14:1205-15.

15. Ratcliffe J, Longworth L, Young T, Bryan S, Burroughs A, Buxton M. Assessing health-related quality of life pre- and post-liver transplantation: A prospective multicenter study. Liver Transpl 2002;8:263-70.

16. Abell TL, Van Cutsem E, Abrahamsson H, et al. Gastric electrical stimulation in intractable symptomatic gastroparesis. Digestion 2002;66:204-12.
17. Lin Z, Forster J, Sarosiek I, McCallum RW. Treatment of diabetic gastroparesis by high-frequency gastric electrical stimulation. Diabetes Care 2004;27:1071-6.

18. van der Voort IR, Becker JC, Dietl KH, Konturek JW, Domschke W, Pohle T. Gastric electrical stimulation results in improved metabolic control in diabetic patients suffering from gastroparesis. Exp Clin Endocrinol Diabetes 2005;113:38-42.

19. McCallum RW, Snape W, Brody F, Wo J, Parkman HP, Nowak T. Gastric electrical stimulation with Enterra therapy improves symptoms from diabetic gastroparesis in a prospective study. Clin Gastroenterol Hepatol 2010;8:947-54.

20. Hasler WL. Methods of gastric electrical stimulation and pacing: A review of their benefits and mechanisms of action in gastroparesis and obesity. Neurogastroenterol Motil 2009;21:229-43.

21. Familoni BO, Abell TL, Voeller G, Salem A, Gaber O. Electrical stimulation at a frequency higher than basal rate in human stomach. Dig Dis Sci 1997;42:885-91.

22. Sogabe M, Okahisa T, Tsujigami K, et al. Ultrasonographic assessment of gastric motility in diabetic gastroparesis before and after attaining glycemic control. J Gastroenterol 2005;40:583-90.

23. Stevens JE, Jones KL, Rayner CK, Horowitz M. Pathophysiology and pharmacotherapy of gastroparesis: current and future perspectives. Expert Opin Pharmacother 2013;14:1171-86.

24. McCallum R, Lin Z, Wetzel P, Sarosiek I, Forster J. Clinical response to gastric electrical stimulation in patients with postsurgical gastroparesis. Clin Gastroenterol Hepatol 2005;3:49-54.

25. Ouelaa W, Ghouzali I, Langlois L, et al. Gastric electrical stimulation decreases gastric distension-induced central nociception response through direct action on primary afferents. PLoS One 2012;7:e47849.

26. Moga C, Harstall C. Health Technology Assessment Report \#37: Gastric Electrical Stimulation (Enterra ${ }^{\mathrm{TM}}$ Therapy System) for the Treatment of Gastroparesis. Edmonton, Alberta: Alberta Heritage Foundation for Medical Research, 2006.

27. Abell T, McCallum R, Hocking M, et al. Gastric electrical stimulation for medically refractory gastroparesis. Gastroenterology 2003;125:421-8.

28. O'Grady G, Egbuji JU, Du P, Cheng LK, Pullan AJ, Windsor JA. High-frequency gastric electrical stimulation for the treatment of gastroparesis: A meta-analysis. World J Surg 2009;33:1693-701.

29. Chu H, Lin Z, Zhong L, McCallum RW, Hou X. Treatment of high-frequency gastric electrical stimulation for gastroparesis. J Gastroenterol Hepatol 2012;27:1017-26.

30. National Institute for Health and Care Excellence (NICE). Interventional Procedure Guidance 489. Gastroelectrical Stimulation for Gastroparesis. <www.nice.org.uk/guidance/ipg489/> (Accessed October 1, 2014). 


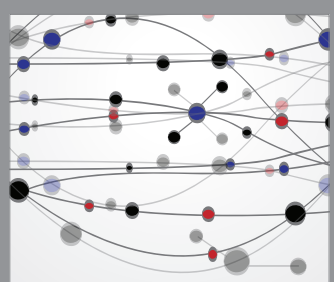

The Scientific World Journal
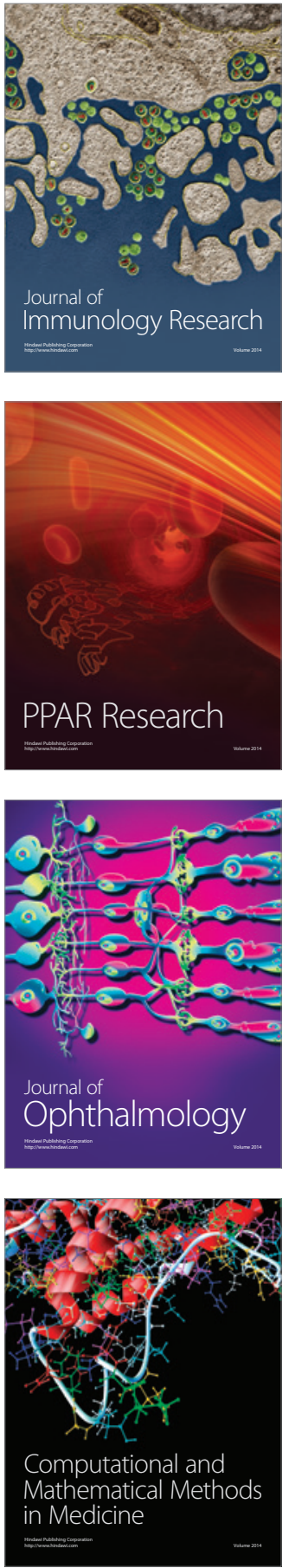

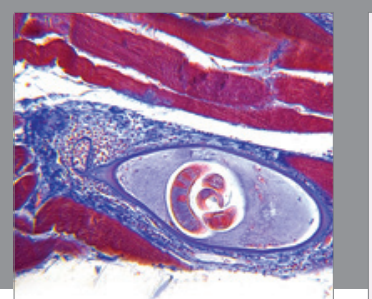

Gastroenterology Research and Practice

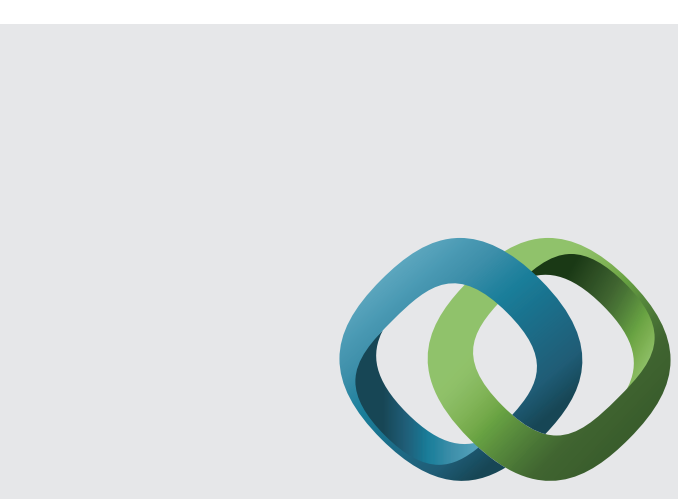

\section{Hindawi}

Submit your manuscripts at

http://www.hindawi.com
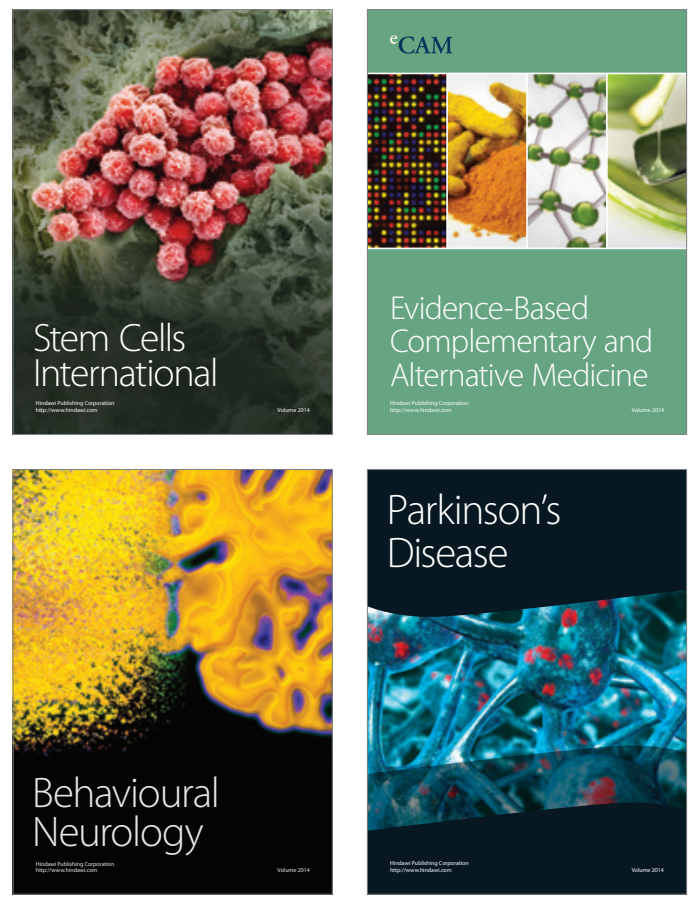
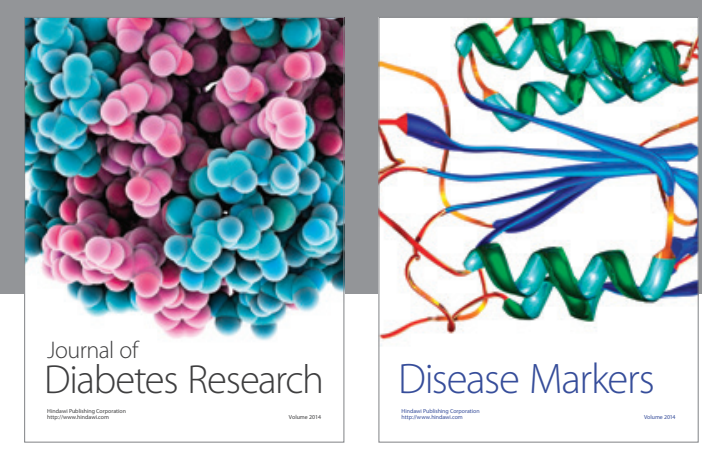

Disease Markers
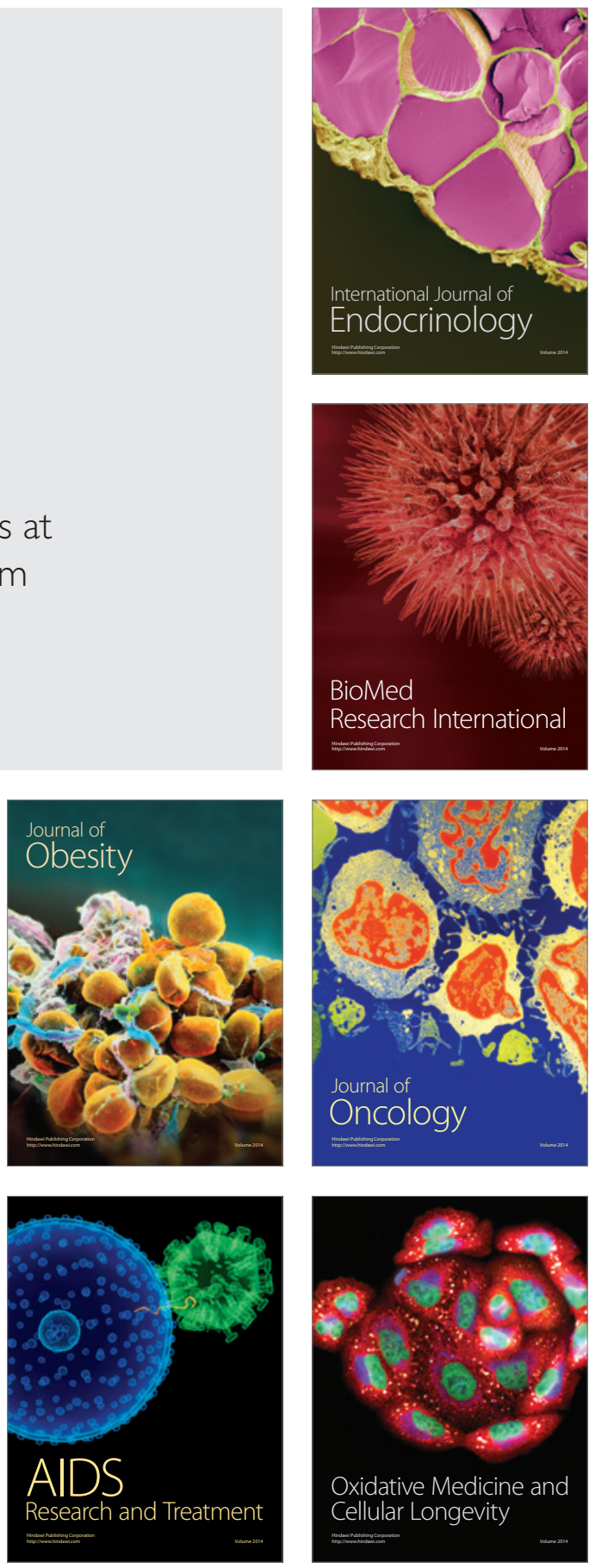